\title{
REPENSANDO A TRAJETÓRIA DO CURSO DE ESPECIALIZAÇÃO EM PRECEPTORIA RESIDÊNCIA MÉDICA E PRECEPTORIA NO SUS E SEUS IMPACTOS NA VIDA PROFISSIONAL/NA VIDA ACADÊMICA
}

\author{
Ana Carolina Alvares Lavigne de Lemos Ta \\ Universidade Estadual de Santa Cruz (UESC) \\ aclavigne@uol.com.br \\ Meire Núbia Santos de Santana \\ Universidade Estadual de Santa Cruz (UESC) \\ meirenubia@yahoo.com.br \\ Eliana Santos Goldman Pinto \\ Universidade Estadual de Santa Cruz (UESC) \\ eliana.sgp@gmail.com \\ Maria Conceição Scaldaferri Fernandes \\ Universidade Estadual de Santa Cruz (UESC) \\ mcscaldaferri@yahoo.com.br \\ Verônica Ferreira de Souza Fernandes \\ Universidade Estadual de Santa Cruz (UESC) \\ vecafs@yahoo.com.br
}

\begin{abstract}
Resumo
Esse trabalho teve como objetivo descrever e discutir a trajetória de docentes do curso de Medicina da Universidade Estadual de Santa Cruz nos Cursos de Especialização Preceptoria em Residência Médica e Preceptoria no SUS, promovidos pelo Instituto Sírio Libanês Ensino e Pesquisa, bem como analisar os impactos da aprendizagem na vida profissional dos mesmos. Além disso, apresentar o relato do percurso trilhado em busca de conhecimentos, assim como o registro das experiências, as percepções acerca do processo de aprendizagem e seus efeitos na prática profissional. O caminho metodológico realizado foi constituído a partir da descrição das atividades educacionais propostas pelo curso, entre elas: situação problema, narrativa, oficina, compartilhamento da viagem, aprendizagem autodirigida, portfólio e projeto aplicativo. Buscou-se estabelecer um diálogo entre as experiências vivenciadas durante o período de março a novembro de 2017 nos referidos cursos de pós-graduação com o referencial teórico sobre metodologias ativas no processo ensino-aprendizagem, com a literatura referente ao exercício da preceptoria no Sistema Único de Saúde e outros aportes teóricos sobre metodologias inovadoras. Conclui -se que os cursos instigaram a reflexão e apontaram pistas para auxiliar na formação de profissionais de saúde, forneceram apoio pedagógico para reiterar as Diretrizes Curriculares Nacionais como modelo no Curso de Graduação em Medicina da Universidade Estadual de Santa Cruz (UESC), solidificar o uso de metodologias ativas de ensino-aprendizagem e fortalecer a articulação ensino-serviço-comunidade e a adoção do paradigma da integralidade. Enfim, forneceram subsídios para adquirir o perfil de competência de preceptoria estabelecido pela Instituição formadora.

Palavras-chave: Aprendizagem. Preceptoria. Formação profissional em saúde.
\end{abstract}




\title{
RETHINKING THE TRAJECTORY IN THE SPECIALIZATION COURSE IN PRECEPTORIA MEDICAL RESIDENCE AND PRECEPTORIA IN SUS AND ITS IMPACTS IN PROFESSIONAL LIFE / IN ACADEMIC LIFE
}

\begin{abstract}
This study aimed to describe and discuss the trajectory of professors of the medical course of the State University of Santa Cruz in the Specialization Courses in Medical Residency and Preceptory in SUS, promoted by the Instituto Sírio Libanês Teaching and Research, as well as analyzing the impacts of learning on their professional lives. Also present is the report of the path traveled in search of knowledge, as well as the record of experiences, perceptions about the learning process and its effects on professional practice. The methodological path was made based on the description of the educational activities, proposed by the course, such as problem situation, narrative, workshop, trip sharing, selfdirected learning, portfolio and application design. It was sought to establish a dialogue between the data extracted from the experiences exercised during the period from March to November of 2017 in the educational activities in the referred postgraduate courses with the theoretical reference on active methodologies in the learning teaching process, with the literature referring to the exercise of the preceptory in the Unified Health System and other theoretical contributions on types of education. It was concluded that the courses instigated reflections and pointed out clues to assist in the training of health professionals, it was provided pedagogical support reiterating the National Curricular Guidelines as a model in the Graduation Course in Medicine of UESC (State University of Santa Cruz), to solidify the use of active teaching-learning methodologies and strengthen the articulation of community/service/teaching and the adoption of the integrality paradigm. Finally, they provided subsidies to acquire the preceptor competency profile established by the training institution.
\end{abstract}

Keywords: Learning. Preceptory. Professional training in health.

\section{REPENSAR LÁ TRAYECTORIA DEL CURSO DE ESPECIALZACIÓN EN PRECEPTORÍA RESIDECIA MÉDICA Y PRECEPTORÍA EN SUS Y SUS IMPACTOS EN LA VIDA PROFESIONAL/EN LA VIDA ACADÉMCA}

\begin{abstract}
Resumen
Esse trabajo tuvo como objetivo describir y discutir la trayectoria de los docentes del curso de medicina de la Universidad Estatal de Santa Cruz en los cursos de Especialización Preceptoría en Residencia Médica y Preceptoría en SUS, promovido por el Instituto Sírio Libanê Docencia y Investigación, así como analizar los impacto del aprediaje en su vida profissional. Además, presentar el relato del camino recorrido en la búsqued del conocimento, así como el registro de experiencias, percepciones sobre el processo de aprendizaje y sus efectos en lá prática profesional. El camino metodológico tomado se construyó a partir de la descripción de las actividades educativas propuestas por el curso, entre ellas: situación problemática, narrativa, taller, viajes compartidos, aprendizaje autodirigido, portafolio y proyecto de aplicación. Se intentó establecer un diálogo entre las experiencias de marzo a noviembre de 2017 en los referidos cursos de posgrado con el marco teórico sobre metodologías activas en el proceso de enseñanza-aprendizaje, con la literatura referente al ejercicio de la preceptoría en el Sistema Único de Salud y otros aportes teóricos sobre metodologias innovadoras. Se concluye que los cursos propocionaron la reflexión y señalaron pistas para ayudar en la formación de los profesionale de la salud, brindó apoyo pedagógico para reiterar los Lineamientos Curriculares Nacionales con el modelo en la Licenciatura en Medicina de la Universidad Estatal de Santa Cruz (UESC), solidificar el uso de metodologías activas de enseñanza-aprendizaje y fortalecer la articulación enseñanza-servicio-comunidad y la adopción del paradigma de la integralidad. Finalmente,otorgaron subsidios para adquirir el perfil de competencia de preceptoría estabelecido por la Institución formadora.
\end{abstract}

Palabras clave: Aprendizaje. Preceptoría. Formación profesional en salud. 


\section{INTRODUÇÃO}

Atualmente, pensar em novas práticas de saúde baseadas numa assistência integral do indivíduo e da coletividade se torna um desafio para o profissional de saúde, cuja formação, em geral, está vinculada a uma pedagogia ainda fragmentada, que pouco dialoga com a realidade e as demandas do serviço. Contribuir para uma formação que leve o (futuro) profissional de saúde a intervir de forma crítico-reflexiva na produção do cuidado, é cada vez mais debatido e percebido como necessário para todos os atores envolvidos.

Tendo em vista essa nova vertente metodológica, que integra ensino-serviço, os cursos de Especialização Preceptoria em Residência Médica (PRM) e Preceptoria no SUS (PSUS) realizados pelo Instituto Sírio Libanês Ensino e Pesquisa em parceria com o Ministério da Saúde (MS), na modalidade semipresencial, utilizam Metodologias Ativas (MA) na abordagem pedagógica. "A metodologia ativa de ensino é considerada um instrumento de transformação, uma vez que parte da leitura de um problema real para gerar aprendizagem, inspirando quebra de protocolos" (PINTO et al, 2018). Possibilita, dessa forma, a partir da problematização, instigar o discente a refletir, examinar e posicionar-se de forma crítica, levando-o a despertar sua autonomia, curiosidade e tomadas de decisões de forma individual ou coletiva, baseandose em contextos e práticas sociais nos quais estão inseridos (BORGES;ALENCAR, 2014).

De acordo com Lima (2017), utilizando a problematização para formar e capacitar profissionais de saúde, as Metodologias Ativas (MA) se constituem como uma estratégia que promove atitude reflexiva e crítica da sua práxis e a integração de diversos saberes. Nessa perspectiva, o uso das MA proporciona independência, pois coloca o discente como protagonista do seu aprendizado, estimulado para estudar de forma contínua. Entretanto, muitos estudantes têm dificuldade de adaptação, tendo sentimento de perda por um longo período, como apontam Marin et al (2010, p 17-18) em seu estudo:

\footnotetext{
(...) ocorre uma abrupta mudança do método tradicional para as metodologias ativas e, então, sentem-se perdidos na busca de conhecimento, principalmente em disciplinas básicas (....) e que tais conteúdos ficam poucos explorados ( ) gera insegurança, requer grande esforço dos atores envolvidos no processo e exige mudança de comportamento, maturidade e organização dos estudantes.
}

Os autores ainda destacam as potencialidades do método, como a aproximação do discente à realidade, a preparação do trabalho em grupo, a associação das disciplinas e o âmbito biopsicossocial, bem como a integração dos ciclos básico e clínico (MARIN et al, 2010). Diversas são as ferramentas que constituem o arcabouço pedagógico das MA que influenciaram na constituição da Espiral Construtivista (EC) (Lima, 2017), metodologia de escolha dos cursos de PRM e PSUS. A EC é problematizadora, toma como base a teoria

Cidadania em Ação: Revista de Extensão e Cultura, Florianópolis (SC), v.4, n.2, jul./dez. 2019. 
sociointeracionista e uma abordagem dialógica para gerar aprendizagem significativa (LIMA, 2017). A espiral é utilizada para dar conotação de movimento que perpassa diversas fases e novas descobertas no processo ensino-aprendizagem, como descreve Lima (2017, pg. 427-428):

\begin{abstract}
Em relação aos movimentos da espiral, a identificação de problemas, formulação de explicações e elaboração de questões de aprendizagem foram denominadas "síntese provisória". A busca por novas informações, a construção de novos significados e a avaliação constituíram uma "nova síntese". Considerando a teoria dialética do conhecimento, a "síntese provisória" corresponde ao momento de síncrese, como uma visão global e inicial da realidade, e a "nova síntese", aos momentos de análise e síntese. A partir da busca, a "nova síntese" representa a possibilidade de reconstrução dos saberes à luz da ciência.
\end{abstract}

Corroborando esses pensamentos, Lima et.al (2014) afirma que

\begin{abstract}
a espiral construtivista retrata este movimento de significados e ressignificados que o sujeito vai descobrindo e suas reflexões vão se materializando à medida que percebe a necessidade e possibilidades de intervenção e transformação da sua realidade. Estes movimentos acontecem de forma articulada e todas as etapas do processo ensino- aprendizagem são importantes no desenvolvimento de capacidades desse sujeito.
\end{abstract}

Partindo desses pressupostos, a inserção nos cursos de especialização do Instituto Sírio Libanês Ensino e Pesquisa representava a possibilidade de adquirir conhecimento de novas abordagens didáticas e técnicas pedagógicas que possibilitassem a qualificação da prática docente e subsidiasse a atualização dos módulos (disciplinas) ofertados, assim como de colaborar no processo de trabalho dos profissionais que compõem as equipes de Saúde da Família, que constituem cenários de prática do módulo PIESC (Práticas de Integração EnsinoServiço-Comunidade). Essas disciplinas são ministradas na rede de atenção básica em saúde, espaços de formação profissional extramuros da Universidade.

Vale ressaltar que, nestes últimos anos, estamos vivendo uma crise sem precedentes no sistema público de saúde do nosso País, em todos os âmbitos, mas principalmente no municipal, o que afeta diretamente as instituições formadoras nas disciplinas/módulos que utilizam a rede municipal como campo de práticas, o que compele o docente a buscar estratégias para superar as diversidades/empecilhos/obstáculos no exercício da prática profissional.

Nessa perspectiva, esse estudo tem como objetivo narrar e refletir sobre a trajetória da aprendizagem nas referidas pós-graduações, assim como evidenciar as mudanças relacionadas à prática profissional dos docentes do curso de graduação de Medicina da Universidade Estadual de Santa Cruz (UESC) participantes dos cursos de especialização PRM/PSUS.

Cidadania em Ação: Revista de Extensão e Cultura, Florianópolis (SC), v.4, n.2, jul./dez. 2019. 


\section{METODOLOGIA}

Trata-se de um estudo descritivo que relata as experiências acadêmicas vivenciadas no período de março a dezembro de 2017, por docentes do curso de graduação em Medicina da UESC, nos Cursos de Especialização em Preceptoria de Residência Médica (PRM) e Preceptoria no SUS (PSUS), promovidos pelo Instituto Sírio Libanês Ensino e Pesquisa em parceria com o MS, com apoio do Conselho Nacional de Secretários de Saúde (CONASS) e do Conselho Nacional de Secretarias Municipais de Saúde (CONASEMS).

Os cursos de especialização PRM e PSUS estabeleceram/definiram previamente o cronograma/calendário e construíram o contrato didático com os discentes logo na execução do primeiro módulo. Utilizaram abordagem pedagógica baseada em problemas (ABP), em equipes (TBL) e educação a distância (EAD).

Funcionaram na modalidade semipresencial, com encontros mensais, carga horária total de 360 horas, sendo exigido dos especializados carga horária mínima de $75 \%$ nas atividades presenciais. Além dessa exigência, para receber a certificação é necessário o cumprimento de

outros requisitos, tais como: obter avaliação de desempenho satisfatório nas atividades educacionais, e atingir conceito satisfatório no trabalho de conclusão de curso (elaborado individualmente) e no projeto aplicativo de intervenção na realidade (confeccionado em grupo).

Os docentes do curso de Medicina da UESC, apesar de já terem titulação de mestre e ou doutor, participaram do processo de seleção para os cursos de especialização anteriormente referidos, motivados pelo anseio de qualificação profissional, tanto para uma nova possibilidade de inserção profissional futura - a Residência Médica -a Residência Multiprofissional, quanto

por uma necessidade imediata de consumo das 'novas' ferramentas pedagógicas para a graduação em Medicina, onde já atuavam.

Salienta-se que o projeto didático-pedagógico norteador do processo de ensinoaprendizagem na formação do profissional médico do curso de Medicina da Universidade Estadual de Santa Cruz (UESC) é calcado em metodologias ativas, e a oportunidade de participar de uma especialização que utiliza a mesma metodologia vem ao encontro da necessidade, de alguns docentes, de aprofundamento teórico da temática.

Na primeira semana fomos apresentados à metodologia e à proposta do curso, que só reforçaram a pertinência das ações a serem desenvolvidas com o grupo de alunos interessados e ávidos por novos conhecimentos e experiências. A primeira situação-problema nos levou exatamente a refletir sobre as metodologias ativas e a elaborar diversas questões que foram discutidas no encontro seguinte.

As questões levantadas pelo grupo foram as seguintes:

Cidadania em Ação: Revista de Extensão e Cultura, Florianópolis (SC), v.4, n.2, jul./dez. 2019. 
1- O que é metodologia ativa?

2- Qual o fundamento teórico das metodologias ativas?

3- Quais são as metodologias ativas?

4 O que se espera da aplicação da metodologia ativa na formação dos profissionais de saúde?

5- Vale a pena trabalhar com a metodologia ativa? As experiências são exitosas ou não?

As palavras-chave para o levantamento bibliográfico naquele momento foram: "metodologia ativa" e "formação profissional em saúde".

Outro ponto alto desse primeiro encontro foi a viagem educacional com a exposição do filme Hipócrates. Esse filme gerou muitos sentimentos contraditórios ao nos depararmos com a realidade de um serviço hospitalar que é campo de prática de diversos residentes médicos. Acredito que essa provocação que o curso nos proporcionou foi bem instigante para que, logo no início, pensássemos em que profissional, futuro preceptor, queremos e devemos ser.

O segundo módulo foi marcado pela divisão de um novo grupo denominado "Afinidade", que foi dividido pela facilitadora com base em critérios de similaridade nas características dos membros do grupo e na possibilidade de elaboração de um projeto aplicativo factível. Outra experiência bastante frutífera que teve início neste segundo módulo foi trabalhar com TBL. Essa proposta pedagógica nos força a trabalhar em equipe, exercitar a escuta ao outro, negociar, pactuar a melhor resposta para o grupo mesmo não concordando em alguns momentos. Essa ferramenta evidencia aspectos da personalidade dos colegas às vezes bem difíceis de conduzir como intransigência, impaciência e resistência àquela situação.

Os módulos seguintes possibilitaram identificar pontos fundamentais da espiral construtivista como uma metodologia ativa de ensino-aprendizagem. Principalmente os movimentos articulados e desencadeados a partir do disparador (narrativas, situação- problema e/ou outros) são etapas educacionais que se movimentam e retroalimentam. De forma participativa, procuramos explorar a espiral construtivista, focando na identificação de problemas; formulando explicações; elaborando questões; construindo novos significados e avaliando todo o processo e o resultado alcançado. Esse conteúdo contribuiu para conhecer novas ferramentas e utilizá-las no processo ensino-aprendizagem na nossa prática profissional. 


\section{RESULTADOS E DISCUSSÃO}

\section{A CONSTRUÇÃO DA NOSSA TRAJETÓRIA NOS CURSOS DE PRECEPTORIA RESIDÊNCIA MÉDICA E PRECEPTORIA NO SUS}

Na nossa trajetória nos cursos de especialização PRM e PSUS, destacamos o contributo da confecção do projeto aplicativo, que consistiu em desenvolver habilidades para sistematizar ideias e recursos para intervir em uma determinada realidade. Esse momento permitiu vivenciar a dinâmica para identificação, priorização e explicação de problemas, detecção dos atores sociais e elaboração do plano de ação, servindo de subsídio para praticar o desenvolvimento do pensamento estratégico, a análise da situação-problema no contexto do SUS e a confecção de propostas para atingir tais objetivos.

A cada programação mensal dos cursos era possível aprimorar o nosso conhecimento teórico sobre planejamento estratégico em saúde, trabalhado por Carlos Matus e Mário Testa, cujo tema já é trabalhado na disciplina do PIESC, tanto teorizando como vivenciando, com os alunos do curso de Medicina, as etapas do Planejamento e Programação Local em Saúde(PPLS) nos territórios adscritos às unidades de saúde da família, locais que são cenários da nossa prática docente.

Vasconcelos Filho (1978, p. 10) definiu Planejamento estratégico como "uma metodologia de pensamento participativo utilizada para definir a direção que a empresa deve seguir, através da descoberta de objetivos válidos e não-subjetivos”. Afunilando essa concepção para o setor saúde, o Planejamento Estratégico, segundo Giovanella (1990), parte da premissa de que há o rompimento de normativas que se impõem sobre a realidade, devendo-se em cada ação alcançar o máximo de liberdade. Seguindo essa linha de pensamento, a autora considera como ponto importante a análise e construção da viabilidade política, quando se admite o conflito entre forças sociais e visões próprias existentes no contexto da situaçãoproblema na qual se planeja.

Muito interessante foi analisar a nossa realidade e detectar problemas que afetam o avanço do SUS nos espaços em que transitamos na condição de docente em cenários de prática, como usuários que utilizam os serviços ofertados, como preceptores que acompanham seus alunos. Portanto, uma oportunidade de problematizar situações vividas no cotidiano,de elaborar propostas viáveis de solução e contribuir para mudança da realidade. Para Caleman et al (2016 p.17), "a construção do projeto aplicativo representa uma oportunidade concreta para traduzirmos nossa ação como sujeitos que desejam transformar a realidade".

A elaboração do projeto aplicativo representou uma produção trabalhosa, exigiu o envolvimento do grupo, a capacidade de revisar, rever, realizar ajustes, reformular, enfim,

Cidadania em Ação: Revista de Extensão e Cultura, Florianópolis (SC), v.4, n.2, jul./dez. 2019. 
exercitar a paciência. Porém, o desejo de alterar a realidade, enfrentar um problema identificado e fazer mudança na situação motivou o grupo a realizar reuniões extras, fora dos encontros presenciais do curso e investir na confecção do referido projeto. Destacamos a articulação do conhecimento prévio com os conteúdos atuais, a busca da literatura para entender os termos de referência.

Vale ressaltar uma atividade que marcou a nossa trajetória nos referidos cursos de especialização, que foi o exercício de dramatizar e vivenciar os papéis de preceptor, residente e observador de encenações, cujo disparador foi a exibição de vídeos sobre a atuação de residentes, seja em visita domiciliar ou em atendimento na unidade de saúde. A atividade se inicia com a exibição de um vídeo-simulação que nos leva a observar os conteúdos e as atitudes nas cenas/nos diálogos: em seguida assumimos os papéis dos personagens e dramatizamos, vivenciando vários papéis.

Esse movimento de se colocar no lugar do outro e pensar formas diferente de agir mexeu com o nosso emocional. A reflexão mais importante que ficou para nós e,de forma geral,para os outros especializandos, foi a de como sair do "eu acho que...", "eu acho que falta..." para uma abordagem mais problematizadora. O desafio maior é sair do prescritivo e achar um meio mais efetivo de agir, e que crie menos resistência.

Nas primeiras encenações, ficou explícito como estão enraizados nos profissionais de saúde, a metodologia do ensino tradicional e o processo de ensino-aprendizagem anacrônico, em que o preceptor é detentor do saber, e cabe ao mesmo prescrever condutas aos "residentes neófitos", pois apesar do conhecimento sobre MA, das pesquisas realizadas durante o curso de especialização, do avanço na compreensão da literatura expressado nas atividades, principalmente da síntese provisória, ainda é muito forte a influência do paradigma biomédico flexneriano, da conduta prescritiva, autoritária, vertical, unidirecional, na qual cabe ao residente ouvir as orientações e acatar as indicações do preceptor.

Esse cenário também se faz presente na educação que, como apontam Maldaner et al (2010), ainda que criticada por mais de um século, hoje em dia deixa vestígios da pedagogia tradicional que acontece nas salas de aulas, tendo em vista que o professor é detentor do conhecimento e o deposita em seus alunos "vazios". Ao final da matéria, os alunos precisam provar, através da avaliação, que adquiriram o conhecimento. A hora da avaliação servirá unicamente para aprovar ou reprovar esse aluno, mas não tem o propósito de trazer alguma reflexão sobre a prática pedagógica utilizada pelo professor (MALDANER et al, 2010).

De forma a mudar tais paradigmas, participamos de várias Oficinas de Trabalho (OT), ficando perceptível a evolução do grupo a cada dramatização e incorporação dos papéis de

Cidadania em Ação: Revista de Extensão e Cultura, Florianópolis (SC), v.4, n.2, jul./dez. 2019. 
preceptor, residente e observador. Nas avaliações, evidenciamos as mudanças nas posturas e na forma de interagir com os residentes, o crescimento na habilidade de instigá-lo, na capacidade de questionar e levar o discente a refletir sobre suas atitudes e as dos outros.

Em vários encontros ocorridos durante o curso, também foram marcantes as OT com dramatização, quando foram vivenciados diversos papéis, intitulada rodada de negociação, permitindo desenvolver a capacidade de se colocar no lugar do outro, a capacidade argumentativa para defender as ideias, a tolerância e a busca de consenso. Tal atividade se assemelha à técnica de "role play ${ }^{1}{ }_{1}$ ", que é muito interessante. Passa por experienciar as dificuldades do processo de integração ensino-serviço, o jogo e a defesa de interesses. Também destacamos outros produtos importantes para o nosso aperfeiçoamento profissional, a exemplo da autoavaliação, da avaliação interpares e da avaliação da facilitadora.

Consideramos que a avaliação formativa é imprescindível para proporcionar reflexão aos participantes do curso. Uma excelente oportunidade de "se olhar no espelho" para "ver sua imagem refletida" e "ver a sua imagem na visão do outro". E para poder colher informações que ajudem a repensar a própria conduta e contribuir para o crescimento dos colegas e da facilitadora, sinalizando pontos positivos e negativos nas atitudes, nos modos e nos comportamentos adotados no transcorrer do curso de especialização.

Enfim, reconhecer as conquistas, os avanços, as fragilidades na trajetória da pósgraduação são oportunidades de melhorar o desempenho, dar novos significados, traçar metas e firmar compromissos visando atingir o perfil nas áreas de competência da saúde, na gestão e educação, definido pelos cursos de especialização PRM e PSUS.

a avaliação somativa e formativa são formas complementares que visam conhecer e garantir os melhores resultados de processos e programas educacionais. (...) A avaliação somativa tem como objetivo avaliar se o aluno assimilou os conteúdos fornecidos durante determinado período, (...) foca mais no resultado final do que na trajetória percorrida pelo estudante durante a aquisição dos conhecimentos e habilidades. (...) a avaliação formativa pressupõe que o ato de avaliar não faz sentido por si só, e sim que ele deve ser parte integrante de todo processo de ensinoaprendizagem. (BORGES; MIRANDA; SANTANA; BOLLELA, 2014, p. 324-325)

\footnotetext{
${ }^{1}$ De maneira geral, o role-play pode ser definido como uma técnica na qual os alunos são convidados a atuar em determinado contexto, interpretando papéis específicos. Solicita-se que os alunos atuem de acordo com o esperado em uma situação real. Como resultado da encenação, todos os alunos envolvidos na atividade irão aprender algo sobre a situação, o contexto proposto e/ou os personagens (RABELO e GARCIA, 2015 p.587).
}

Cidadania em Ação: Revista de Extensão e Cultura, Florianópolis (SC), v.4, n.2, jul./dez. 2019. 
Também permitiu adquirir vários dos conteúdos das ações-chave que fazem parte do perfil da área de competência da educação, formação profissional e produção de conhecimento em saúde, estabelecido pelo Instituto Sírio Libanês Ensino e Pesquisa como perfil de competência do preceptor, com destaque para a identificação de necessidades e oportunidade de aprendizagem com os estudantes e como próprio profissional e preceptor, para o desenvolvimento de atividades educativas a partir das necessidades identificadas, respeitando saberes prévios e favorecendo a descoberta de novas capacidades, superando limitações e dificuldades (OLIVEIRA et al, 2017).

É preciso enfatizar o crescimento dos especializandos no uso de MA nas encenações das oficinas, quando ficou pertinente o novo constructo teórico e sua aplicabilidade, a capacidade instrumental e a desenvoltura nessa estratégia educacional. Essa evolução deixou nítido que a turma foi adquirindo o perfil de competência da preceptoria, aquele estabelecido pelo Instituto Sírio-Libanês de Ensino e Pesquisa.

Além dessas atividades educacionais descritas, é importante relatar, nesse percurso, o significado de outras: a aprendizagem autodirigida e o compartilhamento das viagens. A primeira é um convite à investigação, busca, exploração e análise de informações e conhecimentos. De forma livre e direcionada, o aluno pode percorrer, projetar, sistematizar e depois, em grupo, socializar e filtrar a essência do conteúdo para responder as questões de aprendizagem. Já o compartilhamento da viagem permite diversificar a aprendizagem utilizando o componente artístico. Os filmes abordam temáticas que possibilitam uma reflexão sobre a vida profissional e a vida pessoal, contemplam o ensaio do compromisso social, levam a meditar sobre o papel de cidadão em nossa comunidade. De maneira leve, mexe com os sentimentos, com valores e posicionamentos, enfim, com o nosso papel social na sociedade em que vivemos. Nesse módulo, a viagem educacional foi referente ao filme "Um golpe do destino", e foi fantástico rever essa obra cinematográfica com um objetivo educacional. Foram revelados aspectos bem importantes que não tinham chamado tanto a nossa atenção anteriormente.

Essa experiência nos permitiu fazer uma viagem interior a nossos sentimentos mais íntimos e reavaliar nossas atitudes pessoais e profissionais. Experienciar um momento de doença e fragilidade faz o profissional refletir bastante e trabalhar mais a empatia com seus pacientes. As cenas desse longa-metragem mostram que é muito mais importante a confiança que depositamos nos nossos cuidadores, sejam eles médicos, enfermeiros ou outro profissional, do que a competência técnica por si só. 
Nesse relato, ainda salientamos a importância da elaboração do Projeto Terapêutico Singular (PTS) em equipe interdisciplinar, e podemos afirmar que a experiência ajudou a ampliar nossa visão para análise do caso em estudo, assim como colaborou para identificar possibilidades e estratégias de enfrentamento da situação, ou seja, para construir propostas de condutas de forma coletiva. O PTS é destinado a situações consideradas mais complexas e reúne um conjunto de ações terapêuticas articuladas a partir de discussões em equipe multidisciplinar, podendo contar com apoio matricial. Trata-se de uma variação de um caso clínico (MELO et al, 2013).

Apesar de ser considerada uma ação inovadora do SUS, pois utiliza o contexto interdisciplinar para promover um cuidado baseado no princípio da integralidade, busca uma ampliação do olhar sobre o usuário através da multiprofissionalidade (MELO et al, 2013). As equipes ainda enfrentam algumas dificuldades na implementação do PTS, fazendo-se necessário sobrepor tais questões em busca de espaços coletivos na produção do cuidado, como destacado no trecho abaixo:

\begin{abstract}
(...) os estudos apontam que, quanto às limitações para a efetivação do projeto terapêutico singular nas equipes de saúde, maior atenção deve ser dada às questões de melhoria da comunicação e integração entre a equipe, a construção de espaços multidisciplinares nos serviços de saúde para discussão do PTS e a formação acadêmica que deve estar voltada para a prática da abordagem integral (MELO et al, 2013 p.202) .
\end{abstract}

A análise do caso fez refletir a fragmentação da rede de cuidados no atual modelo assistencial, o incipiente acolhimento, a inexistência de protocolos integrados, a falta de responsabilização, de vínculo e articulação interinstitucionais, assim como a ausência do processo de educação permanente, entre outras deficiências, e reafirma a certeza da necessidade de reorganização da rede para garantir a longitudinalidade do cuidado.

Além disso, serviu para reforçar o nosso empenho na prática docente nos cenários de produção do cuidado, que são cenários de produção pedagógica, no intuito de auxiliar o discente na ampliação do olhar do sujeito epistêmico, de forma a colaborar no fortalecimento da articulação, no compartilhamento de saberes, práticas e responsabilidades entre as categorias profissionais, para garantir o estabelecimento de processos dialógicos, a horizontalização das relações de poder diante das necessidades dos pacientes e, também, contribuir para despertar o compromisso social do estudante na busca da resolubilidade das demandas dos usuários, respeitando a sua alteridade. 


\title{
DESLOCAMENTO E IMPACTOS NA PRÁTICA DOCENTE
}

Refletir sobre o percurso do nosso processo de aprendizagem constituiu-se em um grande desafio. É usar óticas para perceber os caminhos percorridos, os modos como desempenhamos as atividades, analisar a nossa atuação e identificar, através dos episódios, se houve qualificação, ressignificação da prática docente, se alcançamos as expectativas iniciais e se atingimos o perfil de competências estabelecido pelos cursos. É fazer uma viagem retrospectiva para refletir sobre nossas experiências, analisar os processos de aprendizagem provocados pelas mesmas e ainda evidenciar situações que mais impactaram.

É uma verdadeira imersão para verificar se conseguimos romper com a atuação prescritiva e se incorporamos conhecimentos nas dimensões técnica, humana e políticoeconômica, e competências nas áreas de saúde, gestão e educação, de forma a desempenhar nosso papel para estimular o estudante a observar a realidade, identificar as necessidades da população e atuar na construção do cuidado, incentivando a escuta. Enfim, implicar o discente no desenvolvimento das habilidades necessárias ao trabalho interdisciplinar, à complementaridade dos saberes.

Nesses vários mergulhos, concluímos que os cursos de especialização PRM e PSUS indicaram caminhos, forneceram ferramentas, proporcionaram a construção de conhecimentos e saberes e possibilitaram exercitar a preceptoria. Entretanto, podemos afirmar que a preceptoria se constrói no cotidiano, sendo necessário o exercício de reflexão diária. O essencial é instigar o residente para colaborar na sua formação, auxiliando na consolidação de valores éticos e no compromisso com a política de saúde (SUS). Mais ainda, deve ficar vigilante para manter o pensamento estratégico, ampliar a visão de mundo, procurar corrigir as distorções no percurso, persistir no sonho de transformar a realidade, estar disposto a iniciar sempre e buscar estabelecer parcerias com o mesmo propósito.

Rozendo e Lima (2015 p.783) afirmam que

\begin{abstract}
a preceptoria é um espaço privilegiado de discussão, construção de conhecimento, e reflexão sobre o fazer cotidiano. A medida que se colocam em contato com as várias dimensões de sua prática profissional, mediado pela presença do estudante e do professor, os preceptores podem ser confrontados com seu próprio fazer, questionando-o, revisitando-o e refazendo. As tensões cotidianas que a própria preceptoria e o trabalho interprofissional produzem podem ser propulsores de reflexão e recondução da prática, seja ela clínica ou pedagógica.
\end{abstract}

Vale ressaltar que, historicamente, o processo ensino-aprendizagem na formação dos profissionais de saúde sofreu a influência do modelo biomédico flexneriano, cujo paradigma enfatiza uma formação fortemente biológica, centrada no indivíduo, tendo como base aulas predominantemente teóricas, com organização disciplinar do currículo estruturado entre o ciclo 
básico e o profissional, sob o formato de períodos, muitas vezes com matérias estanques (MITRE et.al, 2008).

Além disso, a literatura aponta que o processo ensino-aprendizagem sempre utilizou metodologias tradicionais, nas quais o docente é considerado o detentor do conhecimento, assumindo o papel de transmissor de informações, e o aluno fica na posição de receptor de conteúdo, cabendo-lhe memorizar, fixar e reproduzir os assuntos com eficiência, tendo como consequências a produção da fragmentação do conhecimento, separação entre o corpo e a mente dos indivíduos, desconsideração pelos elementos psicológicos, sociais e ambientais no processo de adoecimento dos sujeitos, e uma valorização da técnica em detrimento dos aspectos humanísticos na prestação do cuidado (MITRE et.al, 2008).

O Sistema Único de Saúde, que é ordenador da formação de profissionais, e o estabelecimento de requisitos para o mercado de trabalho a fim de atender às necessidades de saúde da população provocaram debates, nas instituições reguladoras do setor educação, que resultaram em mudanças nas diretrizes nacionais curriculares de graduação na área de saúde. $\mathrm{E}$, consequentemente, as instituições de ensino superior se adequaram às exigências, rompendo com o modelo biomédico, seguindo a lógica da responsabilidade social e apresentaram projetos pedagógicos para formar profissionais habilitados para atuar nas redes de atenção à saúde e organizar o processo de trabalho na perspectiva dos princípios do SUS.

Um exemplo do investimento para habilitar trabalhadores da saúde na perspectiva de consolidar o SUS são esses cursos de especialização de preceptoria em Residência Médica e Preceptoria no SUS, que têm como objetivo contribuir para a melhoria da atenção à saúde do referido sistema por meio da capacitação de profissionais que atuam como preceptores em cenários reais do cuidado à saúde, visando à reorientação articulada dos modelos de atenção e de formação, buscando a ampliação da qualidade do acesso e a integralidade do cuidado em redes de atenção à saúde.

Salientamos que nossas expectativas em relação aos movimentos de aprendizagem em ambos os cursos de especialização foram atingidas, e dentre elas destacamos: a troca de experiências, o material didático, a habilidade técnica para desenvolver atividades educacionais utilizando metodologias ativas. Necessário ressaltar que não fomos preparados para ensinar. A nossa experiência deriva principalmente do nosso conhecimento no campo em que atuamos como profissional de saúde, somada à própria vivência na docência e ao curso de especialização em docência na saúde, e afirmamos que os cursos de especialização PRM e PSUS forneceram apoio pedagógico para: reiterar as Diretrizes Curriculares Nacionais (DCN) como modelo no Curso de Graduação em Medicina da UESC, solidificar o uso de metodologias ativas de ensino-

Cidadania em Ação: Revista de Extensão e Cultura, Florianópolis (SC), v.4, n.2, jul./dez. 2019. 
aprendizagem, fortalecer a articulação ensino-serviço-comunidade na adoção do paradigma da integralidade. Portanto, como descrito, foram muitos os ganhos, vários os deslocamentos, evidenciando o nosso crescimento profissional.

Já desde o nosso embarque na trajetória da referida especialização, vivenciamos momentos ricos e adquirimos suporte para debater, com pares da nossa Instituição de origem (UESC), sobre metodologias ativas e outros temas que têm auxiliado a revigorar o projeto pedagógico do curso de Medicina da UESC, e também identificar estratégias para que possamos consolidar o desenho do curso, bem como resistir às intempéries da prática docente.

Desse modo, no decorrer desse processo construtivo, que trouxe o relato das nossas experiências nos cursos de especialização e os significados dessa trajetória, podemos afirmar que elas provocaram inquietações, estimularam indagações, possibilitaram a troca de vivências e experiências, e que foram muitos os elementos colaborativos, a exemplo dos materiais didáticos (narrativas, textos, vídeos, devolutivas etc) que instigaram a reflexão e apontaram pistas para auxiliar na formação de profissionais de saúde.

Ainda podemos declarar que essa experiência descrita possibilitou aprimorar a nossa prática docente, com vista a reafirmar o compromisso com a consolidação do Sistema Único de Saúde, como também reiterar que o SUS é ordenador da formação profissional,dialogando com as atribuições da participação na formação profissional, expressas especificamente no Art. 200, parágrafo III, seção II, capítulo II da Constituição Federal de 1988, onde estabelece que compete ao SUS “ordenar a formação de recursos humanos na área de saúde”.

\section{CONSIDERAÇÔES FINAIS}

A metodologia dos cursos de especialização de Preceptoria em Residência Médica (PRM) e Preceptoria no SUS (PSUS) e as atividades desenvolvidas pela tutora permitiram que o grupo crescesse, cada um com suas características marcantes, mas todos com espaço para se posicionar, colocar suas ideias, discutir os diferentes pontos de vista e chegar a novas conclusões.

A dinâmica de trabalhar com a espiral na construção do conhecimento permite que todos se exponham e busquem novos conhecimentos para contribuir com o grupo, que participem das discussões e recebam as contribuições dos colegas. Tudo isso enriqueceu muito nossas referências. As ponderações feitas pela tutora foram bem pertinentes e consistentes ao longo de todos os módulos, e reiteramos o contributo e o legado deixados por essa experiência na nossa prática docente.

Também consideramos que a formação profissional deve atender às necessidades dos

Cidadania em Ação: Revista de Extensão e Cultura, Florianópolis (SC), v.4, n.2, jul./dez. 2019. 
serviços de saúde e às demandas da população, e que acontecerá isso a partir de: valorizar o vínculo entre as instituições de ensino e os serviços de saúde, enfatizar a inclusão do princípio da integralidade como um eixo da formação em saúde e reiterar a indissociabilidade entre teoria e prática.

Além disso, devemos repensar o modelo curricular hegemônico na saúde, refletir sobre os pressupostos básicos que persistem norteando o ensino das profissões da área de saúde, criticar a influência do paradigma biomédico flexneriano e a visão cartesiana no processo ensino-aprendizagem, assim como reconhecer que o perfil profissional resultante dos postulados do arquétipo biomédico não atende às demandas dos modelos assistenciais alternativos propostos pelo SUS.

Ao longo desses anos, vários questionamentos emergiram e resultaram na construção e organização de novas DCN dos cursos de graduação da área da saúde, e dentro das instituições de ensino superior sugiram movimentos com o intuito de procurar cumprir as propostas construídas nas diretrizes curriculares, e acreditamos que, para avançar na consolidação das mudanças curriculares, garantir a interdisciplinaridade dos saberes, possibilitar uma dinâmica inovadora das relações sociais entre educando e educador, promover a construção do conhecimento científico contextualizado e proporcionar o fortalecimento da integração teoria e prática, faz-se necessário continuar a investir em educação permanente para os docentes.

É necessário investir e ampliar a oferta de cursos para preceptores, atores fundamentais na formação profissional em saúde, que, historicamente, têm participado e colaborado, sendo pouco valorizados, e têm recebido, de forma incipiente, suporte e condições de trabalho para exercer sua função. Na dissertação de Francijane Oliveira (2014 p. 83-84) os resultados da sua pesquisa junto aos preceptores de Residência Multiprofissional em Saúde da Família na cidade do Recife-PE, levam a supor que

(...) a busca por um sistema de saúde que seja capaz de contribui para minimizar as iniquidades sociais é o fio condutor da prática de preceptoria deste grupo. Contudo, ainda é uma prática exercida de maneira isolada, não há efetivamente envolvimento da gestão e da universidade. A preceptoria, embora defendida institucionalmente, ainda é realizada de forma tal que cada componente permanece em suas respectivas ilhas (...) Outro ponto relevante levantado neste estudo diz respeito ao sentimento de invisibilidade quanto à prática de preceptoria e a falta de reconhecimentos por parte dos gestores e das instituições de ensino superior.

Neste contexto, diante do exposto, podemos inferir que apenas a publicação das Diretrizes Curriculares Nacionais (DCN) não é suficiente para assegurar a concretude das mudanças na formação profissional que normatizam e norteiam o referido processo, mas a educação permanente é um dos caminhos para sensibilizar os educadores (sejam docentes ou

Cidadania em Ação: Revista de Extensão e Cultura, Florianópolis (SC), v.4, n.2, jul./dez. 2019. 
preceptores), suscitar mudanças no campo do ensino, inserir metodologias ativas, promover o conhecimento emancipador, onde o educando é protagonista do processo ensino-aprendizagem, e acreditamos que essa alternativa resultará na formação de um profissional de saúde ético, solidário, humanista, com senso de responsabilidade social e compromisso com a cidadania.

Além disso, cremos que inovar, transformar, mudar a prática educadora é um desafio diário. Também consideramos que a busca para desenvolver competências nas dimensões do saber, saber ser e saber fazer, está colocada para todos os sujeitos, sejam eles estudantes, professores, trabalhadores/preceptores e ou gestores da saúde. E que a espiral do conhecimento deve ser um movimento constante, contínuo, ininterrupto, necessário e salutar para qualificação dos envolvidos.

Entendemos, portanto, que a formação/transformação deve ocorrer durante a caminhada pelos cenários de atuação de cada ator social, que no movimento de troca constrói-se o sujeito ativo, que percebe e se apropria da visão de mundo do outro. Desta forma, o ser humano cria, recria, produz e reproduz a cultura, tendo como resultado a ressignificação do saber, dos fatos, fenômenos, objetos, necessidades e realidades. 


\section{REFERÊNCIAS}

BORGES, M.C; MIRANDA, C.H.; SANTANA, R.C; BOLLELA, V.R. Avaliação formativa e feedback como ferramenta de aprendizado na formação de profissionais da saúde. Medicina, Ribeirão Preto, v.47, n.3, p. 324-331, 2014.

BORGES, T. S; ALENCAR, G. Metodologias ativas na promoção da formação crítica do estudante: $\mathrm{O}$ uso das metodologias ativas como recurso didático na formação crítica do estudante do ensino superior. Cairu em Revista., ano 3, n.4, p. 119-143, 2014

CALEMAN et al. Projeto Aplicativo: termos de referência. São Paulo: Ministério da Saúde; Instituto Sírio-Libanês de Ensino e Pesquisa, 2016.

CECCIM, R.B. ; FERLA, A.A. Educação Permanente em Saúde. In: PEREIRA, I. B. Dicionário de Educação Profissional em Saúde. 2 ed. rev. e amp. Rio de Janeiro:EPSJV, 2008.

CORTEZ, E. A. et al. Educação permanente, continuada e em serviço: desvendando seus conceitos. Revista Electrónica Trimestral de Enfermeria. n. $29,2013$.

GIOVANELLA, L. Planejamento estratégico em saúde: uma discussão da abordagem de Mário Testa. Cadernos de Saúde Pública, Rio de Janeiro, v.6, n.2, 1990.

LIMA, V.V. et al. Processos educacionais na saúde II. São Paulo: Ministério da Saúde; Instituto Sírio-Libanês de Ensino e Pesquisa, 2014.

LIMA, V.V. Espiral Construtivista: uma metodologia ativa de ensino-aprendizagem. Interface Comunicação Saúde Educação. [s.1], v.21, n.61, p. 421-434, 2017.

LINO, M.M. et al. A realidade da educação continuada na enfermagem nos serviços públicos de saúde em Florianópolis. Online Brazilian Jounal of Nursing, [s.l] v.6, p.1-16, 2007.

MALDANER, J. J.; SETÚBAL, O. A. M. Resquícios da pedagogia tradicional na prática docente: Um relato de experiências a partir do Pibid IFTO-Campus Palmas. In: V CONNEPI Congresso Norte Nordeste de Pesquisa e Inovação, 2010, Maceió AL. Anais do V CONNEPI, 2010.

MARIN, M. J. S. et al. Aspectos das fortalezas e fragilidades no uso das metodologias ativas de aprendizagem. Revista Brasileira de Educação Médica, [s.1], v.34, n.1, p. 13$20,2010$.

MELO, F. A. B. P. Projeto Terapêutico Singular como estratégia de prática da multiprofissionalidade nas ações de saúde. Revista Brasileira de Ciências da Saúde. [s.l], v.17, n.2, p.197-202, 2013.

MITRE, S. M. et al. Metodologias ativas de ensino-aprendizagem na formação profissional em saúde: debates atuais. Revista Ciências Saúde Coletiva, Rio de Janeiro, v.13, 2008, supl. 2. 
OLIVEIRA, F.D. A preceptoria na Estratégia Saúde da Família: o olhar dos profissionais de saúde. Dissertação (Mestrado Profissional em Ciências da Saúde) Universidade Federal do Rio Grande do Norte, 2014.

OLIVEIRA, M.S. de et al. Preceptoria no SUS: caderno do curso 2017. São Paulo: Hospital Sírio-Libanês; Ministério da Saúde, 2017.

PINTO, E.S.G et al. Metodologias ativas no território: a pluralidade dos encontros.v. 4, Suplemento 1 (2018). ISSN 2446-4813: Saúde em Redes.Suplemento, Anais do $13^{\text {a }}$ Congresso Internacional da Rede UNIDA..

RABELO, L.; GARCIA, V. L. Role-play para o desenvolvimento de habilidades de comunicação e relacionais. Revista Brasileira de Educação Médica. [s.1] v.39, n.4, p. 586-596, 2015.

ROZENDO, C. A.; LIMA, P.A.B. Desafios e possibilidades no exercício da preceptoria do Pró- PET Saúde. Interface Comunicação Saúde Educação. [s.1], p.779-791, 2015. supl.9.

VASCONCELHOS FILHO, P. Afinal, o que é planejamento estratégico? Revista de Administração de Empresas, São Paulo, v.18, n.2, p.10, 1978. 